\title{
Prevalence of gestational diabetes mellitus in antenatal women and its associated risk factors
}

\author{
Leila J. Gracelyn*, Saranya N.
}

Department of Obstetrics \& Gynaecology, A.C.S Medical College and Hospital, Chennai-600 077, Tamil Nadu, India

Received: 25 December 2015

Revised: 07 January 2016

Accepted: 08 January 2016

\section{*Correspondence:}

Dr. Leila J. Gracelyn,

E-mail: mleila2008@gmail.com

Copyright: (c) the author(s), publisher and licensee Medip Academy. This is an open-access article distributed under the terms of the Creative Commons Attribution Non-Commercial License, which permits unrestricted non-commercial use, distribution, and reproduction in any medium, provided the original work is properly cited.

\begin{abstract}
Background: Gestational diabetes mellitus (GDM) is an important public health problem in India and its prevalence is steadily increasing. It is one of the common complications during pregnancy affecting both maternal and fetal outcome. The increased prevalence is due to the aging population structure, urbanization, obesity epidemic and physical inactivity. Among the South Asian ethnic groups, Indian women mainly south Indians are developing GDM in highest frequency which emphasizes the significance of universal screening in South Asians. The main objective was to find out the prevalence of Gestational diabetes mellitus according to ADA criteria and to examine its association with a number of risk factors in the pregnant population.

Methods: Hospital based analytical cross sectional study was conducted for 1 year among 500 antenatal women. Fasting blood glucose was measured after which they were given $75 \mathrm{~g}$ oral glucose and plasma glucose was estimated at 1 hour and 2hour. GDM was diagnosed according to ADA criteria. Inclusion criterion was pregnant women attending outpatient department between 24-28 weeks gestation. Exclusion criteria were known diabetic women (pre gestational)/diagnosed having GDM before 24 weeks.

Results: Prevalence of GDM was found to be $11.8 \%$. Gestational diabetes mellitus was found to be significantly associated with age, BMI, past history of PCOS, family history of diabetes, excess weight gain in present pregnancy, GDM in previous pregnancy and previous poor fetal outcome.

Conclusions: Prevalence of GDM is progressively increasing and it was significantly associated with multiple risk factors. Universal screening should be done for all pregnant women for better maternal and fetal outcome.
\end{abstract}

Keywords: Gestational diabetes mellitus, Oral glucose tolerance test, Prevalence, PCOS

\section{INTRODUCTION}

Gestational diabetes mellitus (GDM) is defined as carbohydrate intolerance of variable severity, with an onset or first recognition during pregnancy, whether insulin or only diet modification is used for treatment and whether or not the condition persists after pregnancy. ${ }^{1}$ GDM is one of the common metabolic complications of pregnancy. As a result of maternal hyperglycaemia at 24 28 weeks of gestation, the adverse risk of maternal, fetal, and neonatal outcomes continuously increases. ${ }^{2}$ GDM is associated with maternal complications like preeclampsia, infection, polyhydramnios, caesarean section and fetal problems like sudden intra uterine demise, macrosomia, birth trauma, hypoglycemia, hyperbilirubinemia and respiratory distress syndrome. Not only women with GDM, their offspring's also have increased risk for developing impaired glucose tolerance (IGT), type 2 diabetes (six fold than non GDM women) and obesity in future i.e. two generations are at risk., 
Therefore accurate screening and early diagnosis of GDM is necessary to intervene timely and to obtain better outcome, both for the mother and baby, during and after pregnancy.

\section{METHODS}

Study design: Hospital based analytical cross sectional study.

Study period: One year from October 2014 to September 2015.

\section{Study population}

500 pregnant women of 24-28 weeks of gestation, who attend the outpatient department, OBGY, ACS Medical College, Chennai, India.

\section{Inclusion criteria}

Pregnant women between 24-28 weeks of gestational age attending outpatient department.

\section{Exclusion criteria}

Known diabetic women (pre gestational)/diagnosed having GDM before 24 weeks.

\section{Ethical considerations}

Informed consent was obtained from all the participants at the start of the study. Ethical clearance was taken from the institutional ethical committee before starting the study.

\section{Proforma}

Patients were provided with detailed participant information and informed voluntary consent was taken from them. Detailed clinical history was taken and clinical examination performed. Information about age, obstetric score, gestational age, family history of diabetes, obstetric history, past history, weight gained in present pregnancy was collected. Body mass index was also calculated using pre pregnancy weight. Gestational age was calculated from last menstrual period, confirmed or corrected by ultrasound gestational age. General examination including blood pressure and obstetric examination was done. After an overnight fast of 10-12 hours, fasting sample was taken then 75 grams of glucose was given to them orally and plasma glucose was estimated at 1 and 2 hour. GDM was diagnosed according to ADA criteria.

\section{ADA criteria $^{I}$}

One-step (IADPSG Consensus)
The OGTT should be performed in the morning after an overnight fast of at least 8 hours.

The diagnosis of GDM is made when any of the following plasma glucose values are exceeded:

- Fasting: $\geq 92 \mathrm{mg} / \mathrm{dl}$

- $1 \mathrm{~h}: \geq 180 \mathrm{mg} / \mathrm{dl}$

- $2 \mathrm{~h}: \geq 153 \mathrm{mg} / \mathrm{dl}$

\section{BMI - ICMR Guidelines 5}

- Normal - $18-22.9 \mathrm{~kg} / \mathrm{m}^{2}$

- Overweight - $23-25 \mathrm{~kg} / \mathrm{m}^{2}$

- Obese - > $25 \mathrm{~kg} / \mathrm{m}^{2}$

In our study, we have analysed the prevalence of GDM in pregnancy and associated risk factors for GDM. Categorical data were analysed with the odds ratio, chi square test and the $\mathrm{P}$ value of $<0.05$ was considered statistically significant. SPSS software was used for statistical analysis.

\section{RESULTS}

A total of 500 pregnant women between 24-28 weeks of gestation were evaluated for GDM. Among the 500 women, 59 (11.8\%) were diagnosed having GDM using ADA criteria and the remaining had normal glucose tolerance (Figure 1). Mean gestational age of the study population was $25.65 \pm 1.42$ weeks.

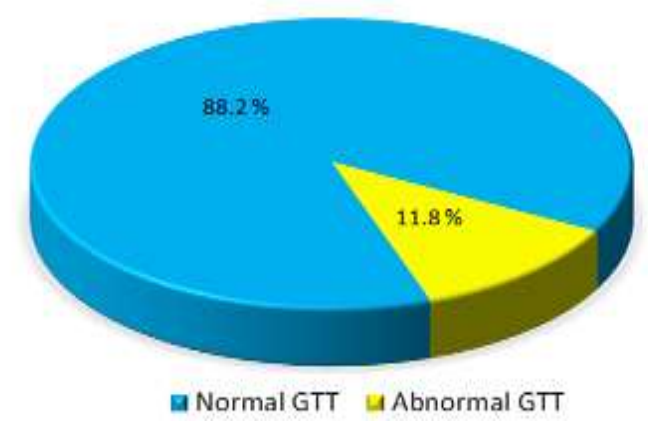

Figure 1: Prevalence of gestational diabetes in antenatal women.

Age

Out of the 500 pregnant women, $47.8 \%$ were between 2630 years and $10.6 \%$ were $31-35$ years Table 1 . The mean age of the study population and GDM women were $26.45 \pm 3.69$ years and $28.47 \pm 3.38$ years respectively. Among the 59 GDM women, $62.71 \%$ belongs to $26-30$ years, followed by $20.3 \%$ of $31-35$ years (Figure 2 ). The correlation between age and GDM was found to be statistically significant, (Odds Ratio 3.92; CI 1.93-7.94) p value 0.00005 as seen in Table 3 . 
Table 1: Socio-demographic risk profile of antenatal women.

\begin{tabular}{|c|c|c|c|}
\hline Variable & Classification of variable & Total number of patients $(500)$ & Percentage $\%$ \\
\hline \multirow{4}{*}{ Age } & $\geq 18-25$ & 206 & 41.2 \\
\hline & $26-30$ & 239 & 47.8 \\
\hline & $31-35$ & 53 & 10.6 \\
\hline & $>35$ & 2 & 0.4 \\
\hline \multirow{3}{*}{ Pre pregnancy BMI } & $<23$ & 387 & 77.4 \\
\hline & $23-25$ & 69 & 13.8 \\
\hline & $>25$ & 44 & 8.8 \\
\hline \multirow{3}{*}{ Gravida } & 1 & 161 & 32.2 \\
\hline & 2 & 218 & 43.6 \\
\hline & 3 & 121 & 24.2 \\
\hline \multirow{2}{*}{ Family H/O Diabetes } & Yes & 50 & 10 \\
\hline & No & 450 & 90 \\
\hline \multirow{2}{*}{ Family H/O GDM } & Yes & 26 & 5.2 \\
\hline & No & 474 & 94.8 \\
\hline
\end{tabular}

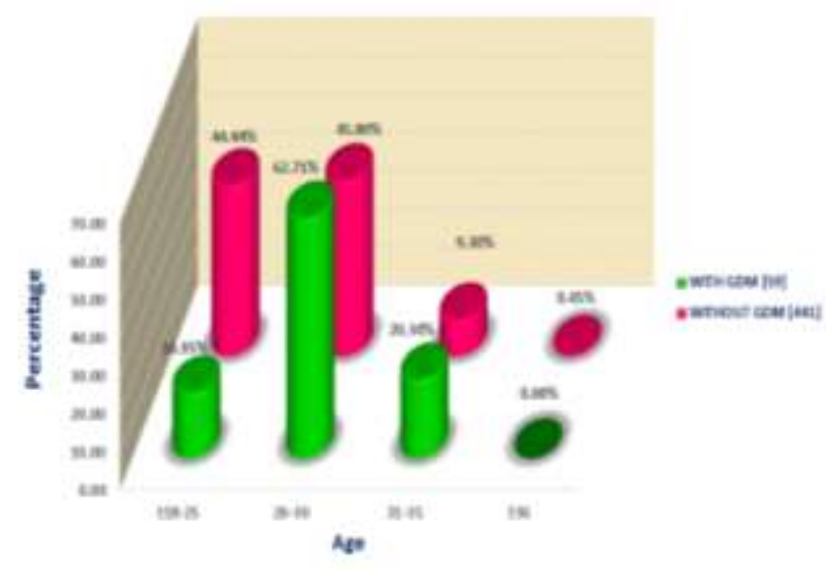

Figure 2: Age wise distribution of GTT abnormalities in antenatal women.

\section{Pre pregnancy BMI}

Among the pregnant women, $22.6 \%$ (113) were obese (95\% CI -18.93-26.27) as seen in Table 2. Mean pre pregnancy BMI of study group was $21.94 \pm 2.68 \mathrm{~kg} / \mathrm{m}^{2}$. If we consider GDM women, the mean BMI was $26.07 \pm 4.44 \mathrm{~kg} / \mathrm{m}^{2}$ and $66.10 \%$ (39/59) were found to be obese compared to $16.78 \%$ of non GDM women. Statistically significant positive correlation was noted between GDM and obesity (OR 7.86; 95\% CI-4.3714.12; p 0.00001) Table 3. Prevalence of GDM was found to be increased with increasing pre pregnancy BMI.

\section{Family history of Diabetes}

Family history of Diabetes was seen in $10 \%$ of study population Table 1. 52.54\% of GDM women had diabetes in their family compared to $4.31 \%$ of non GDM, with
(OR 24.59; CI 12.36-48.89).We found significant positive correlation with $\mathrm{p}$ value of 0.00001 as shown in Table 3. Family history of GDM was present in $18.64 \%$ of GDM women.

\section{Present pregnancy}

\section{Weight gain of more than $8 \mathrm{~kg}$}

Weight gain of more than $8 \mathrm{~kg}$ was present in $8.6 \%$ (43) of pregnant women with 95\% CI 6.14-11.06 (Table 2). Among them 29 had GDM which contributes to $49.15 \%$ (OR 29.48; CI 14.1-61.64). Weight gain of $>8 \mathrm{~kg}$ had statistically significant correlation with GDM (p 0.00001) Table 3.

\section{Hypertension}

Only $2 \%$ of study population had hypertension with $95 \%$ CI 0.77-3.23, as shown in Table 2. Hypertension was present in only $3.39 \%$ of GDM (OR 1.89; CI 0.39-9.16). Association between GDM and hypertension was not statistically significant with p value of 0.751 (Table 3).

\section{History of PCOS}

History of PCOS was present in $9 \%$ of study population with 95\% CI 6.49-11.51 (Table 2). 59.32\% (35/59) of GDM women had history of PCOS in past compared to $2.27 \%$ of non GDM women (OR 62.85 CI 27.84-141.88). Significant positive correlation was noted between PCOS and GDM with p value of 0.00001 (Table 3).

\section{History of GDM}

$18.64 \%$ of GDM women had GDM in their previous pregnancy with OR 8.95 (CI 3.68-21.75). Statistically 
significant association was present between GDM and past history of GDM (p 0.00001) Table 3.

Table 2: Clinical and biochemical profile of antenatal women.

\begin{tabular}{|llll|}
\hline Variables & Number & Percentage \% & $95 \%$ CI \\
\hline Weight gain $>$ 8kg in pregnancy & 43 & 8.6 & $6.14-11.06$ \\
\hline History of polycystic ovaries & 45 & 9 & $6.49-11.51$ \\
\hline Hypertension & 10 & 2 & $0.77-3.23$ \\
\hline Obesity & 113 & 22.6 & $18.93-26.27$ \\
\hline Previous H/O GDM & 22 & 4.4 & $2.6-6.2$ \\
\hline Previous H/O preterm/pprom & 19 & 3.8 & $2.1-5.48$ \\
\hline Previous H/O stillbirth & 18 & 3.6 & $1.97-5.23$ \\
\hline Previous H/O macrosomia & 43 & 8.6 & $6.14-11.06$ \\
\hline Previous H/O term IUD & 20 & 4 & $2.28-5.72$ \\
\hline Abnormal GTT & 59 & 11.8 & $8.97-14.63$ \\
\hline
\end{tabular}

Table 3: Association of GDM with various risk factors.

\begin{tabular}{|c|c|c|c|c|c|}
\hline Variable & $\begin{array}{l}\text { Classification of } \\
\text { variable } \\
\text { Total number in the } \\
\text { group (500) }\end{array}$ & $\begin{array}{l}\text { Number of } \\
\text { patients } \\
\text { with GDM } \\
\text { [59] }\end{array}$ & $\begin{array}{l}\text { Chi-square } \\
\text { value }\end{array}$ & $\begin{array}{l}\text { Odds ratio } \\
\text { [ } 95 \% \mathrm{Cl} \text { of odds ratio] }\end{array}$ & $P$ value \\
\hline \multirow{2}{*}{ Age } & $>25$ years $[294]$ & 10 & \multirow{2}{*}{15.124} & \multirow{2}{*}{$3.92[1.93-7.94]$} & \multirow{2}{*}{$0.00005^{*}$} \\
\hline & $\leq 25$ years $[206]$ & 49 & & & \\
\hline \multirow{2}{*}{$\begin{array}{l}\text { Family history of } \\
\text { diabetes }\end{array}$} & Yes [50] & 31 & \multirow{2}{*}{129.21} & \multirow{2}{*}{$24.59[12.36-48.89]$} & \multirow{2}{*}{$0.00001^{*}$} \\
\hline & No [450] & 28 & & & \\
\hline \multirow{2}{*}{$\begin{array}{l}\text { Weight gain }>8 \mathrm{~kg} \text { in } \\
\text { pregnancy }\end{array}$} & Yes [43] & 29 & \multirow{2}{*}{134.16} & \multirow{2}{*}{ 29.48[14.1-61.64] } & \multirow{2}{*}{$0.00001^{*}$} \\
\hline & No [457] & 30 & & & \\
\hline \multirow{2}{*}{$\begin{array}{l}\text { History of polycystic } \\
\text { ovaries }\end{array}$} & Yes [45] & 35 & \multirow{2}{*}{199.92} & \multirow{2}{*}{$62.85[27.84-141.88]$} & \multirow{2}{*}{$0.00001 *$} \\
\hline & No [455] & 24 & & & \\
\hline \multirow{2}{*}{ Hypertension } & Yes [10] & 2 & \multirow{2}{*}{0.100} & \multirow{2}{*}{$1.899[0.39-9.16]$} & \multirow{2}{*}{0.751} \\
\hline & No [490] & 57 & & & \\
\hline \multirow{2}{*}{ Obesity } & Yes [113] & 39 & \multirow{2}{*}{56.92} & \multirow{2}{*}{$7.86[4.37-14.12]$} & \multirow{2}{*}{$0.00001 *$} \\
\hline & No [387] & 20 & & & \\
\hline \multirow{2}{*}{ Previous H/O GDM } & Yes [22] & 11 & \multirow{2}{*}{28.54} & \multirow{2}{*}{$8.95[3.68-21.75]$} & \multirow{2}{*}{$0.00001 *$} \\
\hline & No [478] & 48 & & & \\
\hline \multirow{2}{*}{$\begin{array}{l}\text { Previous H/O } \\
\text { preterm/PPROM }\end{array}$} & Yes [19] & 9 & \multirow{2}{*}{20.58} & \multirow{2}{*}{$7.75[3.00-19.99]$} & \multirow{2}{*}{$0.00001 *$} \\
\hline & No [481] & 50 & & & \\
\hline \multirow{2}{*}{ Previous H/O stillbirth } & Yes [18] & 9 & \multirow{2}{*}{22.51} & \multirow{2}{*}{$8.64[3.27-22.77]$} & $0.00001 *$ \\
\hline & No [482] & 50 & & & \\
\hline Previous $\mathrm{H} / \mathrm{O}$ & Yes[43] & 25 & 0002 & 09 & 0957 \\
\hline macrosomia & $\mathrm{No}[457]$ & 34 & 0.002 & $0.42-2.10]$ & 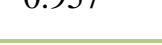 \\
\hline Previous $\mathrm{H} / \mathrm{O}$ term & Yes [20] & 11 & 33.15 & $11.00[4.33-27.88]$ & $0.00001 *$ \\
\hline IUD & No [480] & 48 & 53.13 & $11.00[4.53-21.00]$ & 0.00001 \\
\hline
\end{tabular}

\section{Past obstetric history}

PPROM/Preterm delivery

PPROM/preterm delivery was present in $3.8 \%$ of study population with CI 2.1-5.48 (Table 2). $18.64 \%$ of GDM women had similar problem compared to $2.49 \%$ of non GDM women (OR 7.75; CI 3.00-19.99). GDM had significant positive correlation with PPROM/preterm delivery in previous pregnancy ( $\mathrm{p}-0.00001)$ Table 3.

\section{Stillbirth}

$3.6 \%$ of study population had previous stillbirth with $95 \%$ CI $1.97-5.23$ (Table 2) compared to $15.25 \%$ of GDM women only $2 \%$ of non GDM had previous stillbirth (OR 8.64; CI 3.27-22.77). Statistically 
significant association was present between GDM and previous stillbirth (p 0.00001) Table 3.

\section{Term IUD}

Term IUD was present in $4 \%$ of study population with 95\% CI 2.28-5.72 (Table 2). $18.64 \%$ of GDM women had term IUD compared to only $2 \%$ of non GDM (OR 11; CI 4.33-27.88). GDM had significant positive correlation with term IUD (p 0.00001) Table 3.

\section{Macrosomia}

Among the pregnant women $8.6 \%$ had previous macrosomic baby (birth weight $>4 \mathrm{~kg}$ ) with CI 6.1411.06 (Table 2). $42.37 \%$ of GDM women delivered macrosomic babies in their previous pregnancy compared to $4.08 \%$ of non GDM women (OR 0.93; CI 0.42-2.10) but we found negative correlation between GDM and previous macrosomia (p 0.957) as shown in Table 3.

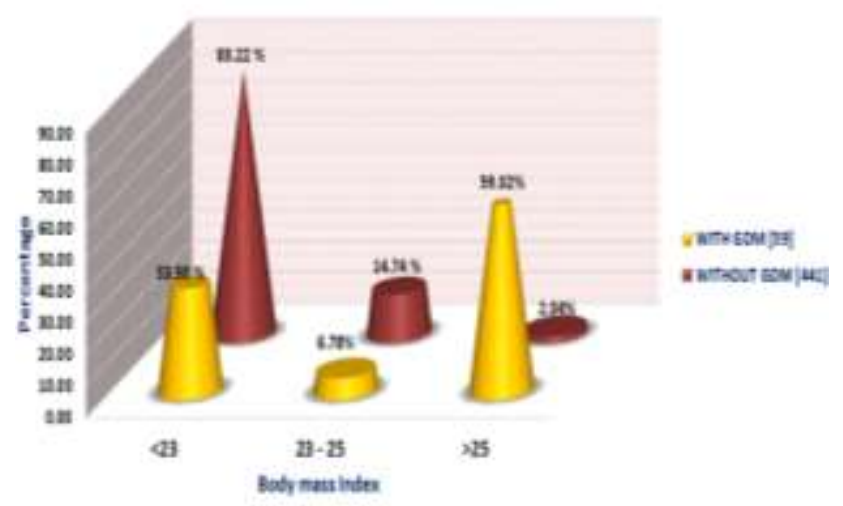

Figure 3: Relation of GTT abnormalities with BMI in antenatal women.

\section{DISCUSSION}

GDM is a common metabolic problem in pregnancy with variable prevalence worldwide and also in different regions of a country, reflects the effect of genetic, demographic, socioeconomic and cultural factors. This variation is also due to different screening methods and diagnostic criteria used to detect GDM. ${ }^{6}$ Prevalence of GDM is increasing globally. In India, the prevalence of GDM was 2\% in 1982 followed by $7.62 \%$ in 1991 and $16.5 \%$ in 2003 with expected rate of 79.4 million in 2030- a $15.1 \%$ increase from $2000 .^{7,8}$ Compared to European females, the South Asian especially Indian females had 11 fold increased risk for GDM. ${ }^{8}$ WHO recommends all pregnant women have to be screened for GDM between 24-28 weeks of gestation. ${ }^{9}$ GDM generally develops during the second and third trimester of the pregnancy, because insulin resistance and diabetogenic effect of pregnancy hormones will be maximum in this period.
In our study out of 500 women, GDM was diagnosed in 59 which contribute to $11.8 \%$. Similarly in Soheilykhah et al study, $10.2 \%$ of pregnant women had GDM. ${ }^{10}$ Seshaiah et al found very high prevalence of $17.7 \%$ in Indian population. ${ }^{9}$ In Das et al study of 300 women, prevalence of GDM was $9.4 \%$ in Kanika et al study, $8.33 \% .^{11,12}$ Rajput et al noticed a prevalence of $7.1 \%$ in Haryana, Nilofer et al screened only high risk group in Karnataka and found an incidence of $6 \% .^{13}$

According to Sreekanthan et al study $75 \%$ of GDM women were above 25 years of age. ${ }^{14}$ In our study, we noticed $62.71 \%$ women with GDM were 26-30 years with mean age being $28.47 \pm 3.38$ years. In Kalyani et al study, $56 \%$ of GDM females were more than 25 years of age with mean age of $24.16 \pm 3.63$ years. ${ }^{12}$ In Kalra et al study the mean age of GDM women was $27.1 \pm 2.44$ years. ${ }^{15}$ The prevalence of pregnant women having GDM steadily increasing with age from $1.7 \%$ in women less than 25 years to $18 \%$ in $\geq 35$ years. ${ }^{16}$ According to RCOG guidelines, pregnant women below 25 years of age are less prone to develop GDM. Significant relationship was noted between age and GDM. It may be due to increasing educational level and working opportunities. They may be aware of getting GDM with increasing age but never give an importance in their busy schedule. In our study $59.32 \%$ of GDM women were second gravidas and above. Sharma et al documented that prevalence of GDM increased with multigravida. ${ }^{17}$ According to Seshiah et al the prevalence of GDM is rising with gravidity, from $18.1 \%$ in first pregnancy to $25.8 \%$ in grand multies. ${ }^{8}$

According to Sharma et al, BMI >30 was observed in 30 (64\%) GDM women. ${ }^{17}$ Similarly in our study, $66.10 \%$ (39/59) of GDM women were obese. Das et al and Gomez et al. reported that obesity was present in $25 \%$ and $50 \%$ of GDM women. ${ }^{11}$ Kanika et al found $96 \%$ of GDM women had BMI $>30$ and the mean BMI in GDM was $34.3 \mathrm{~kg} / \mathrm{m}^{2}$ but in our study it was $26.07 \pm 4.44 \mathrm{~kg} / \mathrm{m}^{2}{ }^{12}$ In our study we found significant association between obesity and GDM.

If a pregnant woman gained $6 \mathrm{~kg}$ than her prepregnancy weight by 28 weeks, it is considered as normal. ${ }^{18}$ In our study, GDM women gained more weight $(>8 \mathrm{~kg})$ than women with normal glucose tolerance. Saldana et al noted that weight gain was significantly higher in GDM women than non GDM women. ${ }^{19}$ Bo et al had observed that increased blood glucose in pregnancy was a risk factor for higher gestational weight gain. ${ }^{20}$ There is misbelief that over nourishment during pregnancy is essential and hesitancy among pregnant women to do even simple household works due to fear of losing baby, along with lack of exercise and improper diet control plays an important role.

Pregnant women with positive family history of diabetes had higher chances of getting GDM. ${ }^{8,16}$ In our study $52.5 \%$ of GDM women had positive family history of 
diabetes which was $76 \%$ in Soheilykhah et al study. ${ }^{10}$ Similar to our study, Seshiah et al also observed a strong correlation between the family history of diabetes with the development of GDM in pregnancy. ${ }^{8}$ In our study half of the women with GDM had PCOS history, similar to Bibi et al study. ${ }^{21}$ Radon et al, found that half of PCOS diagnosed women developed GDM during pregnancy. ${ }^{22}$ Majority of PCOS women have $\beta$ cell dysfunction which leads to inadequate insulin response to glucose load, combined with the diabetogenic effect of pregnancy may be the cause for development of GDM in PCOS. We found strong correlation between GDM and history of PCOS.

A significant association was noted between history of GDM in previous pregnancy and occurrence of GDM in the index pregnancy, although only small number of pregnant women had past history of GDM. The odds ratio was found to be 8.95 . McGuire et al found an odds ratio of 23 for pregnant women with prior GDM. ${ }^{23}$ In Reece et al study, women who delivered macrosomic baby in previous pregnancy had higher risk for GDM in next pregnancy. ${ }^{24}$ There was no statistically significant association between previous macrosomia and GDM in our study which is in contrast to other studies.

Thus, GDM was found to be associated with multiple risk factors. Universal screening remains useful to identify GDM women in our pregnant population.

\section{CONCLUSIONS}

Prevalence of GDM was found to be $11.8 \%$ among the pregnant women. It was noted that there was statistically significant correlation between age, obesity, excess weight gain in pregnancy, family history of diabetes, history of PCOS, previous history of GDM and gestational diabetes. Promoting healthy lifestyle habits in reproductive age women may alter the modifiable risk factors and prevent development of GDM. Pregnant women should be counselled about the diabetogenic effect of pregnancy and the risk factors for development of GDM. Early diagnosis and appropriate intervention is necessary for optimal maternal and fetal outcome in present and future.

\section{Funding: No funding sources}

Conflict of interest: None declared

Ethical approval: The study was approved by the Institutional Ethics Committee

\section{REFERENCES}

1. American Diabetes Association. Gestational diabetes mellitus. Diabetes Care. 2014;37(Suppl 1):14-80.

2. HAPO Study Cooperative Research Group, Metzger BE, Lowe LP, Dyer AR, Trimble ER, Chaovarindr $\mathrm{U}$, et al. Hyperglycemia and adverse pregnancy outcomes. The New England Journal of Medicine. 2008;358(19):1991-2002.

3. Ferrara A, Hedderson MM, Quesenberry CP, Selby JV. Prevalence of gestational diabetes mellitus detected by the National Diabetes Data Group or the Carpenter and Coustan plasma glucose thresholds. Diabetes Care. 2002;25(9):1625-30.

4. Schwartz R, Teramo KA. Effects of diabetic pregnancy on the fetus and newborn. Semin Perinatol. 2000;24(2):120-35.

5. Misra A, Chowbey P, Makkar BM, Vikram NK, Wasir JS, Chadha D. Consensus statement for diagnosis of obesity, abdominal obesity and the metabolic syndrome for Asian Indians and recommendations for physical activity, medical and surgical management. J Assoc. Physicians India. 2009;57:163-70.

6. Di Cianni G, Volpe L, Lencioni C, Miccoli R, Cuccuru I, Ghio A, et al. Prevalence and risk factors for gestational diabetes assessed by universal screening. Diabetes Res Clin Pract. 2003;62(2):1317.

7. Agarwal S, Gupta AN. Gestational Diabetes.J Assoc Physicians India. 1982;30:203-5.

8. Seshiah V, Balaji V, Balaji MS, Sanjeevi CB, Green A. Gestational diabetes mellitus in India. J Assoc Physicians India. 2004;52:707-11.

9. World Health Organization. Definition and diagnosis of diabetes mellitus and intermediate hyperglycemia: A report of WHO/IDF consultation. Geneva: World Health Organization; 2006.

10. Soheilykhah S, Mogibian M, Rahimi-Saghand S, Rashidi M, Soheilykhah S, Piroz M. Incidence of gestational diabetes mellitus in pregnant Women. Iranian J Reprod Med. 2010;8(1):24-8.

11. Das V, Kamra S, Mishra A. Screening for gestational diabetes and maternal and fetal outcome. J Obstet Gynaecol India. 2004;54:449-51.

12. Kalyani KR, Jajoo S, Hariharan C, Samal S. Prevalence of gestational diabetes mellitus, its associated risk factors and pregnancy outcomes at a rural setup in Central India. Int J Reprod Contracept Obstet Gynecol. 2014;3(1):219-24.

13. Rajput R, Yadav Y, Nanada S, Rajput M. Prevalence of gestational diabetes mellitus and associated risk factors at a tertiary care hospital in Haryana. Indian J Med Red. 2013;137:728-33.

14. Sreekanthan K, Belicita A, Rajendran K, Vijayakumar A. Prevalence of Gestational Diabetes Mellitus in a Medical College in South India: A Pilot Study. Indian Journal of Clinical Practice. 2014;25(4):342-7.

15. Kalra P, Kachhwaha CP, Singh HV. Prevalence of gestational diabetes mellitus and its outcome in western Rajasthan. Indian $\mathrm{J}$ Endocr Metab. 2013;17:677-80.

16. Zargar AH, Sheikh MI, Bashir M, Masoodi SR, Laway BA, Wani AI, et al. Prevalence of gestational diabetes mellitus in Kashmiri women in Indian 
subcontinent. Diabetes Res Clin Pract. 2004;66(2):139-45.

17. Sharma K, Wahi P, Gupta A, Jandial K, Bhagat R, Gupta R, et al. Single Glucose Challenge Test Procedure for Diagnosis of Gestational Diabetes Mellitus: A Jammu Cohort Study. J Assoc Physicians India. 2013;61:558-9.

18. Physiological changes during pregnancy, In: Dutta DC. 21. Textbook of obstetrics, $6^{\text {th }}$ ed New Central Book Agency (P) Ltd. 2004. p.50.

19. Saldana TM, Siega-Riz AM, Adair LS, Suchindran C. The relationship between pregnancy weight gain and glucose tolerance status among black and white women in central North Carolina. Am J Obstet Gynecol. 2006;195(6):1629-35.

20. Bo S, Menato G, Signorile A, Bardelli C, Lezo A, Gallo ML, et al. Obesity or diabetes: what is worse for the mother and for the baby? Diabetes Metab. 2003;29:175-8.

21. Bibi S, Saleem U, Mahsood N. The frequency of gestational diabetes mellitus and associated risk factors at Khyber teaching hospital Peshawar. J Postgrad Med Inst. 2015;29(1):43-6.

22. Radon PA, Mcmahon MJ, Meyer WR. Impaired GTT in preg $\neg$ nant women with PCOs. Obstet Gynocol. 1999;94:174-97.

23. McGuire V, Rauh MJ, Mueller BA, Hickock D. The risk of diabetes in a subsequent pregnancy associated with prior history of gestational diabetes or a macrosomic infant. Paediatr Perinat Epidemiol. 1996;10:64-72.

24. Reece EA, Leguizamon G, Wiznitzer A. Gestational diabetes: the need for a common ground. Lancet. 2009;373:1789-97.

Cite this article as: Gracelyn LJ, Saranya N.

Prevalence of gestational diabetes mellitus in antenatal women and its associated risk factors Int J Reprod Contracept Obstet Gynecol 2016;5:285-91. 